\title{
Ventricular septal rupture following acute myocardial infarction
}

\author{
Nowell Fine MD, Shahar Lavi MD
}

\begin{abstract}
A
58-year-old man presented for evaluation after three days of progressive dyspnea following a prolonged episode of chest discomfort, for which he did not seek medical attention. He had no history of heart disease; however, he did have a history of hypertension and was a current smoker. Physical examination was notable for bibasilar crackles and a harsh holosystolic murmur heard loudest at the left sternal border. The electrocardiogram revealed $Q$ waves in the inferior leads. Transthoracic echocardiography demonstrated that the inferior wall of the left ventricle (LV) was akinetic, and that a $2.1 \mathrm{~cm}$ muscular ventricular septal defect (VSD) was present in the inferior septum (arrow in Figure 1A), which was confirmed by colour Doppler flow (Figure 1B). Coronary angiography showed a
\end{abstract}

proximally occluded right coronary artery and mild irregularities in the left coronary system. Left ventriculography in the left anterior oblique projection demonstrated migration of the pigtail catheter through the VSD and into the right ventricle (RV) (arrowheads in Figure 1C; Video 1 [view online at www.canjcardiol.com or www.pulsus.com]). A second injection was performed after the catheter was repositioned in the LV (Video 2 [view online at www.canjcardiol.com or www.pulsus.com]). Ventricular septal rupture is a recognized complication of acute myocardial infarction. In the present case, it was speculated that the patient had suffered an inferior acute myocardial infarction three days before presentation. The patient was referred for surgical repair of his VSD.
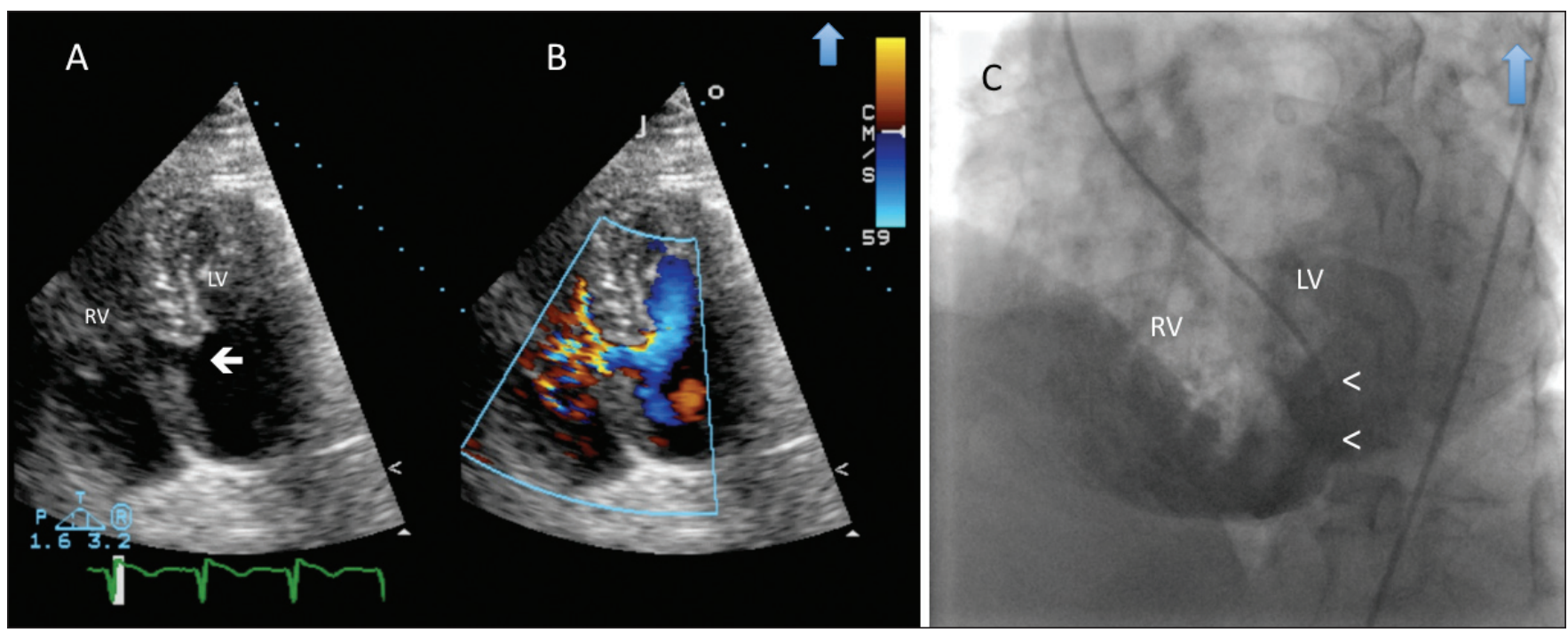

Figure 1

Division of Cardiology, Department of Medicine, London Health Sciences Centre, London, Ontario

Correspondence: Dr Shahar Lavi, University Hospital, 339 Windermere Road, London, Ontario N6A 5A5. Telephone 519-663-3611, fax 519-663-3117, e-mail shahar.lavi@lhsc.on.ca

Received for publication August 18, 2009. Accepted September 5, 2009 